\title{
NOTAS SOBRE OS LIMITES AO EXERCÍCIO DO DIREITO DE CORREÇÃO PATERNAL NO ANTIGO REGIME
}

\author{
Alan Wruck Garcia Rangel \\ NOTES ABOUT LIMITS THE EXERCISE OF PATERNAL \\ PUNISHMENT IN THE ANCIEN RÉGIME
}

\section{RESUMO}

O OBJETIVO DESTE ARTIGO É ABORDAR OS LIMITES DA DISCIPLINA DOMÉstica nO CONTEXTO DO ANTIGO REgIME. TRABALHAMOS COM DUAS QUESTÕES: EM QUAL MEDIDA O DIREITO ROMANO SERVIU DE BASE PARA ELABORACÃO DO CONCEITO DE MODERACÃO AO CASTIGO FÍSICO APLICADO ÀS CRIANCSAS? E EM QUE MEDIDA O CONTROLE DO ENCARCERAMENTO DISCIPLINAR É O RESULTADO DE UMA POLÍTICA RÉGIA PARA OBTER O MONOPÓLIO DO DIREITO DE PUNIR? PARTIMOS DA IDEIA DE QUE OS CONCEITOS E AS CATEGORIAS JURÍDICAS DO DIREITO ROMANO, ESPECIALMENTE AQUELES ELABORADOS DURANTE O BAIXO IMPÉRIO, SERVIRAM AOS JURISTAS, NUM PRIMEIRO MOMENTO, DE FUNDAMENTO AO EXERCíCIO DO DIREITO DE CORREÇÃO, MAS QUE, POSTERIORMENTE, EM RAZÃO DE IMPLICAC̄ÕES POLÍTICAS, E DE TRANSFORMAÇÕES DE ORDEM ANTROPOLÓGICA, O DIREITO ROMANO FOI REINTERPRETADO E ADAPTADO A UM NOVO PARADIGMA DISCIPLINAR. O RESULTADO DESSE ESTUdO É QUE OS LIMITES DO DIREITO DE CORREÇÃO PATERNAL REPRESENTAM, POR UM LADO, O PROCESSO DE CONTROLE SOCIAL REALIZADO PELO ESTADO E, POR OUTRO, O RESQUÍCIO DE UMA MENTALIDADE DISCIPLINAR DE CONCEPÇÃO ROMANO-CRISTÃO.

\section{PALAVRAS-CHAVE}

Mentalidade Jurídica; Controle social; Poder disciplinar; PÁTRIO PODER.

\section{ABSTRACT}

THE AIM OF THIS PAPER IS TO APPROACH THE LIMITS OF THE PATERNAL PUNISHMENT IN THE CONTEXT OF ANCIEN RÉGIME. IN THIS PAPER I EXAMINE TWO QUESTIONS: HOW THE ROMAN LAW WAS THE BASIS FOR ELABORATING THE CONCEPT OF MODERATION FOR CHILDREN'S PHYSICAL PUNISHMENT? AND HOW THE CONTROL OF PRISON DISCIPLINARY SYSTEMS IS THE RESULT OF THE ROYAL POLITICAL MONOPOLY OF PUNISHMENT? I START WITH THE IDEA THAT LEGAL CONCEPTS AND CATEGORIES OF ROMAN LAW, ESPECIALLY THAT OF THE LOWER EMPIRE, SERVED FOR A JURISTS, AT FIRST AS THE FOUNDATION FOR EXERCISING THE PATERNAL PUNISHMENT, BUT SUBSEQUENTLY, DUE TO POLITICAL IMPLICATIONS, AND TRANSFORMATIONS OF AN ANTHROPOLOGICAL ORDER, ROMAN LAW WAS RE-INTERPRETED AND ADAPTED TO A NEW DISCIPLINARY PARADIGM. THE RESULT OF THIS STUDY IS

THAT THE LIMITS OF PATERNAL PUNISHMENT REPRESENT THE PROCESS OF SOCIAL CONTROL CONDUCTED BY THE STATE, AND SECONDLY, THE REMNANT OF A DISCIPLINARY MENTALITY INHERITED FROM THE ROMAN-CHRISTIAN CONCEPTIONS.

\section{KEYWORDS}

LAW MENTALITY; SOCIAL CONTROL; DISCIPLINARY POWER; PATERNAL POWER.

\section{INTRODUÇÃO}

Castigar os filhos, com a finalidade de corrigi-los, é um direito dos pais que subsiste na legislação de muitos países, como França, Brasil, Itália e Inglaterra. ${ }^{1}$ Como bem afirmou B. Schnapper, em um estudo clássico do tema para o século XIX, talvez em nenhum outro país da Europa o direito de os pais castigarem os filhos foi tão forte 
como na França (1991 , p. 523-553). O direito de correction paternelle previsto pelo Código Napoleão permitia aos pais encarcerarem seus filhos a título disciplinar nas casas de correção, e esse direito somente desapareceu após a Primeira Guerra (Decreto-lei de 30 de outubro de 1935). ${ }^{2}$ Ademais, o castigo físico moderado ainda hoje é autorizado pelo Código Civil. ${ }^{3}$ Se o tema é de atualidade, ele não é novo. Já no direito romano, o modo como se deveria proceder ao castigo doméstico foi objeto de discussão na doutrina, sendo inclusive uma matéria prescrita por legislação imperial no século III a.C.. ${ }^{4}$ Igualmente, durante a Idade Média, encontramos esse direito previsto nos costumes locais. Nosso objetivo não é, entretanto, fazer um estudo amplo e exaustivo dos limites do direito de correção - tema que pode englobar um longo período histórico, e sugerir reflexões de natureza social, política e religiosa que ultrapassam o campo estritamente jurídico. Tal tarefa seria impossível em um artigo de algumas páginas. Nosso propósito é bem mais modesto: concentrar o seu estudo entre os séculos XVI e XVIII, e tomar como referência o direito francês.

O estudo situa-se, portanto, nos três últimos séculos do Antigo Regime, tendo como ponto de partida o século XVI e como ponto de chegada a Revolução Francesa. É verdade que esse limite cronológico, muito útil ao direito público, e também à história das instituições políticas, serve pouco ao estudo do direito de correção paternal, já que o Código Civil de 1804 se revela nessa matéria como um continuador direto das instituições do Antigo Regime.

As principais fontes jurídicas utilizadas para este estudo foram as decisões das Cortes régias (Parlements), a doutrina e as normas jurídicas (legislação do direito romano, costumes locais, ordenações baixadas pela chancelaria do poder régio e arrêts de reglement que são verdadeiras medidas de polícia emanadas dos Parlements). Utilizamos também dicionários publicados no final do século XVI e início do XVII para definir termos importantes.

Em sentido próprio, "corrigir" significa recolocar alguém no caminho correto. Decorre daí a ideia de desvio ou alteração de comportamento, ao mesmo tempo que decorre daí a ideia de que existe um comportamento considerado como correto, direito ou normal. É, portanto, por causa de um desvio de conduta que a pessoa merece ser corrigida ou repreendida. Assim, em termos jurídicos, o direito de correção pode ser definido como uma reprimenda feita com autoridade para que a infração cometida não se repita. O direito de correção é, portanto, aplicado sobre atos ilícitos que escapam ao sistema de penas da justiça pública. Esses atos entram no "domínio do proibido" sem serem definidos como crimes. Eles devem ser considerados como torts ou faltas. É difícil classificar precisamente esses atos, porque uma simples conduta considerada como contrária aos bons costumes seria susceptível de correção. Em teoria, não se corrige para reprimir o culpado, mas para emendá-lo, para corrigir os seus erros. O direito de correção inscreve-se, assim, ao contexto da disciplina. 
Neste estudo, o titular do direito de correção, antes de qualquer outro membro da família, é o pai ou a mãe, e o destinatário do castigo, o filho menor legítimo. A minoridade no Antigo Regime se fixa conforme a regra do direito canônico, e ela se divide em três períodos: infans, que dura até ao sete anos, idade cujo menor ou pupilo é incapaz de "dolo e malícia"; impuberdade, que vai dos sete aos quatorze anos de idade; e a puberdade que começa após os quatorze anos de idade até a maioridade - esta se operando com a emancipação ou com atingimento de certa idade -, período em que o menor é considerado responsável pelos seus atos. Os juristas distinguem ainda duas épocas para a impuberdade: a proximi infantiae que, segundo a glosa de Acúrsio (PUPILLUM, D. 50, 17, 111), termina aos dez anos e meio de idade para os filhos, e nove anos e meio para as filhas; e a proximi pubertati. De acordo com esse sistema, o menor em proximi infantiae é considerado irresponsável por seus atos (LAINGUI, 1970, p. 222-225). Entretanto, veremos que o campo da minoridade pode ir além desses limites de idade quando se tratar do direito de correção paternal.

A questão sobre a finalidade do direito de correção é mais complexa e mereceu estudo a parte, ${ }^{5}$ e será aqui tratada de maneira indireta. Nos contentaremos dizer que quando uma criança ou um jovem adulto se comporta de maneira considerada incorreta, inadequada, a medida corretiva reveste-se ao mesmo tempo de caráter educativo e disciplinar.

Nosso propósito é, portanto, situar o estudo no campo do exercício do direito de correção. Em outras palavras, tentaremos responder à seguinte questão: como os pais exercem o direito de correção contra o filho rebelde, e quais os seus limites?

Para responder a essa questão, o tema será tratado sob a óptica da disciplina doméstica. ${ }^{6} \mathrm{O}$ interesse deste estudo é, portanto, demonstrar o processo de transformação da disciplina doméstica que se operou entre os séculos XVI e XVIII por intermédio do direito de correção do pai de família. Esse processo se inscreve no âmbito de mutações de caráter antropológico e também político ocorridas na sociedade nesse período. Trata-se de um fenômeno de disciplina social que se manifesta de forma horizontal em inúmeros setores da vida em sociedade, e que pode também ser identificado de forma vertical por meio do estudo da consolidação do poder de polícia do Estado. ${ }^{7}$ Apesar de que o direito de correção do pai de família assuma função de polícia - o que acarreta um estado permanente de concorrência entre autoridade pública e autoridade doméstica durante o período estudado,$-^{8}$ o tema é aqui tratado de preferência sob o ponto de vista do pátrio poder, e menos sob o ponto de vista do poder de polícia do Estado.

O direito de correção do pai de família toca assim a questão do uso do direito romano na época moderna. Se a noção de patria potestas subsiste no Antigo Regime, essa instituição romana se aclimatiza aos costumes locais franceses e recebe uma concepção diferente. A legislação do direito romano é tratada pelos jurisconsultos 
como um modelo jurídico a ser seguido ou evitado; ela é de certa maneira instrumentalizada por eles. Esse caráter instrumental do direito romano se torna evidente no contexto da disciplina doméstica a partir do século XII, notadamente a partir da penetração do direito romano na França (AUBENAS, 1964). Pode-se dizer que o direito romano assume duas funções específicas: a de ordenador da disciplina doméstica, e a de controlador do pátrio poder. Se o direito romano serviu como instrumento de ordenamento da disciplina doméstica no âmbito dos costumes locais - por exemplo o artigo 65 do Costume da cidade de Montpellier redigido em 1204 (HILAIRE, 1968-1969, p. 434) ${ }^{9}$-, a partir do século XVI ele servirá de preferência como instrumento de controle do pátrio poder.

Abordaremos, assim, em um primeiro momento, os limites jurisdicionais do direito de correção paternal, o que implica conhecer os limites do poder disciplinar no âmbito da magistratura doméstica (I). Em seguida abordaremos os limites materiais do direito de correção, o que implica um estudo do seu conteúdo (II).

\section{OS LIMITES DA MAGISTRATURA DOMÉSTICA}

Os jurisconsultos do Antigo Regime encontraram no direito romano um modelo jurídico para impor limites à jurisdição doméstica. Nesse modelo encontraram regras que habilitam a competência punitiva do magistrado doméstico e, ao mesmo tempo, delimitam o seu campo de exercício. São regras de ordem procedimental que enquadram o direito de correção no campo da disciplina doméstica. Lê-se, assim, em um fragmento do Codex que quando o pai deseja aplicar um remédio mais forte (artiore remedio) no seu filho, ele deve levá-lo diante do juiz local a fim de que este último aplique a sentença ditada pelo pai (C. 8, 46). ${ }^{10} \mathrm{O}$ juiz, neste caso, funciona apenas como executor da sentença prolatada pelo paterfamilias. A autoridade de justiça apenas legitima com o "selo público" a decisão paterna. A autoridade pública é, neste caso, subsidiária à autoridade doméstica. Ainda em um outro fragmento, encontrado no Código Teodosiano, os anciãos da família (senioribus) exercem função de magistrado e podem aplicar uma punição moderada aos jovens da família (minores) com a finalidade de corrigi-los. Aqui o "menor" não é levado ao tribunal para ser punido, a autoridade doméstica exerce o ius domesticae emendationis (direito de emenda doméstica) de maneira direta (C. Teod., 9, 13, 1). ${ }^{11}$

Essas soluções do direito romano se reproduziram nos tribunais do Antigo Regime. Em um aresto de 16 de março de 1556, por exemplo, um pai pede permissão ao tribunal de Grenoble para exercer o seu direito de pátrio poder (iure patria potestatis) para corrigir seu filho "que ele não pôde trazer perante a Corte através de ameaças e reprimendas, nem pela vergonha do vício, nem pelo amor da virtude". Reconhecendo ao pai o direito de admoestação e de emenda, os juízes da Corte encerram o processo e reenviam à jurisdição doméstica o julgamento e a correção das faltas do filho. Ainda é 
atribuído ao pai o poder para condená-lo, em conjunto com os parentes próximos, nas penas que ele considerar necessárias à emenda do filho. De acordo com a sentença, o filho foi condenado a ser encarcerado em uma casa de campo do pai por três meses, sendo-lhe proibido retornar à cidade sob pena de prisão (EXPILLY, 1631, Ch. 43, p. 347-349).

Tal como previsto no direito romano, a justiça pública é subsidiária à justiça doméstica. Os juízes executam a sentença ditada pelo pai, sendo a decisão paterna definitiva e não podendo ser atacada por nenhuma via de recurso. Note-se que, quando os juízes terminam o processo sem julgar o mérito da questão, o poder jurisdicional deles é suspenso, e o meio processual para obter esse efeito jurídico é colocar as partes hors cour (fora da corte). ${ }^{12}$ Em um segundo momento, os juízes reenviam o poder jurisdicional ao pai, e com esse expediente eles reconhecem a competência originária da magistratura doméstica para julgar o filho rebelde. A partir desse momento, o pai de família tem o controle completo da jurisdição e pode decidir entre a aplicação do castigo ou o perdão. Entretanto, quanto à execução da decisão, a justiça doméstica não pode concorrer com a justiça do Rei, sendo defeso ao pai pronunciar uma pena contra o filho. A punição do culpado - e aqui sanção penal opõe-se à sanção disciplinar - é de exclusiva competência da justiça régia. O direito de correção dos pais fica, na maior parte dos casos, restrito a dois tipos de sanção: o castigo físico moderado e o encarceramento.

Se inicialmente o direito romano permitia aos pais de família o auxílio da justiça régia para exercerem o direito de correção, a partir do século XVII a doutrina instrumentaliza o direito romano em proveito do Rei, e afirma que "quando um pai ou uma mãe coloca os seus filhos nas mãos da Justiça por maus-tratos, eles não são mais mestres, mesmo que eles declarem que os filhos sejam inocentes e perdoados" (SERPILlON, 1767, Tit. X, Art. VIII). Doravante o poder jurisdicional dos pais não é reconhecido de maneira absoluta pelos juízes. Dependendo do delito cometido pelo filho e das circunstâncias do fato, a justiça doméstica pode ser afastada, cabendo aos magistrados decidir a punição. Ao contrário do que se pretendia anteriormente, a partir de agora, a autoridade doméstica é subsidiária à autoridade régia. Não cabe mais aos pais decidirem em única instância da sanção ou do perdão do filho. A sentença pronunciada pela autoridade doméstica não é mais definitiva.

Em um primeiro momento, o direito de retratação é retirado da jurisdição doméstica. O direito de os pais perdoarem seus filhos se assemelha ao direito de graça do Rei, e a manifestação desse direito em justiça gera uma concorrência entre pátrio poder e poder régio. Assim, no Parlement de Grenoble, o aresto de 10 de novembro de 1622 condena o filho de Jacques Ducrest à pena de galés perpétua sem considerar o perdão do pai que havia retirado a queixa oferecida contra o seu filho (BASSET, 1738, Liv. 5, T. 10, Ch. 5, p. 235-237). Na realidade, já no final do século XVI a justiça régia havia se demonstrado reticente quanto às absolvições proposta pelos pais 
aos seus filhos. Segundo o aresto de 23 de dezembro de 1577, um filho é levado à justiça por sua mãe sob acusação de maus-tratos. Os juízes o condenam à pena de amende honorable a ser cumprida com "a cabeça descoberta e os pés descalços, e com uma corda no pescoço, e a ser açoitado pelo quarteirão da cidade, e a seis anos de galés"; e o jurista que cita essa decisão diz que o filho teria sido condenado à forca se a mãe não tivesse suplicado aos juízes o seu perdão (ROCHE-FLAVIN, 1682, Liv. 2, T. 5, § 6). ${ }^{13}$ Em um segundo momento, o poder de punir da magistratura doméstica é controlado. Na Corte de Grenoble uma sentença pronunciada em conselho de família é reformada pelos juízes. O filho havia sido condenado por seus parentes a vinte anos de galés (galeres à temps), e declarado indigno a suceder os bens da família. Mas, segundo o aresto do dia 19 de setembro de 1663, o princípio do direito romano foi afastado, e a pena de vinte anos de galés foi agravada para galés perpétua (ROCHE-FLAVIN, p. 235-237).

Essas decisões ilustram a política de repressão que se instaura no decorrer do século XVII, segundo a qual o Estado absolutista detém o monopólio do poder punitivo, sem reconhecer qualquer via de composição privada sobre infrações de interesse público. É neste sentido que no final do século XVIII o jurista Daniel Jousse entende por penas privadas "aquelas que se pronunciam pelos juízes sob demanda da parte civil" (1771, Tit. 3, Ch. 1, p. 38). Assim, se pais e mães conservam ainda o poder para incriminar os filhos rebeldes perante os tribunais, eles ficam, contudo, destituídos do controle da jurisdição; além disso, a condenação do filho pode ser agravada pelo parquet se as circunstâncias do fato exigirem. Se o filho merece uma reprimenda forte, ele pode ser levado à justiça pública, mas o poder de sentença e de clemência dos pais não será exercido de maneira soberana. Segundo as palavras do jurisconsulto JeanGuy Basset, os delitos dos filhos devem ser punidos "para vingar o interesse público, e para que os grandes delitos não sejam dissimulados e acobertados numa escandalosa e perigosa impunidade” (1738, Liv. 4, T. 10, Ch. 6, p. 235-237).

\section{O CONTEÚDO DO DIREITO DE CORREÇÃO PATERNAL E SEUS LIMITES}

Os dois principais meios de exercício do direito de correção são o castigo corporal e o encarceramento disciplinar. Abordaremos em um primeiro momento os limites do castigo corporal (2.1) e depois os limites do encarceramento dos filhos nas casas de correção (2.2).

\section{I A noçÃo de CASTIGo físico MOderado}

A primeira fonte que os jurisconsultos recorriam no Antigo Regime para explicar os limites do castigo físico dos filhos é a última frase de um fragmento do Digesto (D. 48. 5.) no qual se lê que "o pátrio poder deve consistir em piedade, e não em atrocidade" (patria potestas in pietate debet, non in atrocitate consistere). ${ }^{14}$ Nessa pequena 
sentença está todo o conteúdo do direito de correção paternal no Ocidente cristão. Aqui duas palavras merecem destaque: pietate e atrocitate. Para melhor identificar suas nuances, estudaremos a definição jurídica desses dois termos separadamente. Primeiro falaremos da ideia de atrocidade (1) e depois completaremos o estudo com uma explicação sobre a pietas (2).

\section{Atrocidade}

No Antigo Regime - e tal como no direito atual -, o castigo físico moderado é considerado ato lícito. Segundo o direito comum: "O pai pode fustigar o filho, e o fato é presumido como causa de correção" (Pater potest filium verberare, et praesumitur factum causa correctionis, Clementini, 1571, Cap. 6, n. 14, p. 50). O castigo não é apenas um direito, mas um dever dos pais. ${ }^{15} \mathrm{O}$ artigo 611 do Costume da Bretanha prescreve que o pai deve castigar seu filho a fim de que este não cometa infrações contra terceiros (D’ARGENTRE, 1628). ${ }^{16} \mathrm{O}$ castigo tem aqui dupla função preventiva: ele evita os desvios de conduta da criança e impede que os pais se responsabilizem pelas suas faltas. Não existe, portanto, um discurso de proteção à integridade física do menor como conhecemos no direito atual. O castigo físico infligido pelos pais não é um ato terrível que deve sistematicamente ser reprimido pelo direito penal (GARNOT, 1998). Na Bíblia são inúmeras as referências à benevolência do castigo aplicado nos filhos. ${ }^{17}$ Somente o castigo atroz é considerado crime pela doutrina, devendo, neste caso, ser reprimido pela justiça. Qual seria, portanto, o conceito de atrocidade (atrocitas) no Antigo Regime?

Em referência ao texto romano, os jurisconsultos utilizam a expressão "correction atroce" para qualificar o castigo disciplinar não aceitável pelo direito. Mas a noção de atrocitas não é bem definida pela doutrina, nem nos dicionários. ${ }^{18} \mathrm{O}$ seu conceito é bastante elástico e sofreu transformações no decorrer dos séculos. De maneira objetiva, a atrocidade de um crime podia se definir em função da sua natureza (lesa-majestade, parricídio) ou pelas circunstâncias que envolviam o fato. A atrocidade do crime autorizava os juízes a não respeitarem todas as formalidades do processo a fim de acelerar a punição do culpado. A qualificação do crime em atroz permitia, por exemplo, a responsabilidade penal dos impúberes, a punição da tentativa, a responsabilidade penal de parentes, regras consideradas exceções aos princípios de direito observados pela doutrina e pela praxis dos tribunais. No grupo dos crimes atrozes existia, portanto, um sistema jurídico próprio inspirado no sentimento de vingança coletiva que, a partir do século XVI, segundo B. Schnapper (1991b), converteu-se em política de repressão. Entre o que é aceitável e o que se recusa há uma infinidade de escalas que a doutrina tentava esquematizar. Mas de maneira simplista atribuía-se o qualificativo de atrocitas ou de enormitas ${ }^{19}$ a todo ato que ultrapassasse as regras ordinárias observadas e aceitas pela sociedade. Para que o castigo do filho seja qualificado como atroz ou enorme deveria extrapolar os limites do aceitável. E quais são esses limites? 
Duas decisões pronunciadas no século XVII podem nos dar conta da noção de atrocidade no exercício do direito de correção pelos pais. A primeira foi prolatada no dia 12 de fevereiro de 1639. Trata-se de um pai de três filhos que desfere socos e pontapés em suas duas filhas, e arrasta uma delas na rua pelos cabelos, e ao seu segundo filho dá golpes no corpo com vara de nervo de boi e depois com uma correia de couro. O juiz entende que esses atos não são suficientes para caracterizar uma sevícia, e capazes para retirar os filhos da companhia do pai (BONIFACE, 1670, Liv. 1, T. 2, Cap. 1, p. 16). A outra decisão data de 16 de dezembro de 1669, na qual o pai junto com sua segunda mulher expulsa a filha de casa e a deixa dormir no celeiro por vários dias sem comida. A Corte, neste caso, reconhece os maus-tratos, e a filha é colocada em um Mosteiro para lá ser alimentada e mantida sob despesa do pai (BONIFACE, 1689, Liv. 9, T. 4, Cap. 5, p. 673-674).

Ao comparar esses dois julgados, a primeira constatação é que a noção de atrocidade não está unicamente atrelada ao fato de desferir golpes ao corpo da criança. Segundo os dogmas cristãos, o corpo é o lugar e o instrumento por excelência de pecado (SCHMITT, 1998, p. 340). Referindo-se à inclinação do ser humano para cometer pecados, Santo Agostinho diz em sua obra Confissões que "a criança nasce na iniquidade" (Liv. 1, Cap. 7). Inspirados nessa ideia, os juristas não consideravam toda forma de castigo corporal como maus-tratos. O corpo é naturalmente um objeto de pecado, e açoitá-lo pode significar um remédio contra os males do espírito. O pecado se manifestando pelo corpo, e o castigo físico como uma forma de expurgação dos males. ${ }^{20}$ Assim, quando o castigo é infligido com fins corretivos, as lesões corporais provocadas são merecidas à criança. O jurista Joost Damhouder (1555, p. 327-329), na sua obra Pratique et echiridion des causes criminelles diz que:

[...] ocorre frequentemente que se lesa alguém com castigo, ou castigando seus súditos, cuja lesão não é sempre injúria ou dano, porque ela é muitas vezes estimada e reputada como bem feita e obra merecida do que considerada como uma injúria. Pela qual se deve saber que se o pai castiga o seu filho com vergas, mesmo que o castigo seja infligido até a efusão de sangue ...[este ato] é uma santa medicina e um remédio para a sua alma.

Outro dado importante que pode nos indicar o limite da atrocidade é sobre a punição do crime de injúria. ${ }^{21}$ Segundo os criminalistas, para que uma contusão seja considerada lesão corporal e o agressor condenado por crime, esta deve ser "grande et énorme" (DAMHOUDER, p. 327). Portanto, se para punir aqueles que agem com dolo, a lesão provocada na vítima dever ter um grau considerável de ferimento, em se tratando de correção paternal cuja intenção do pai agressor é sempre corretiva, a tolerância ao ato é bastante grande. 
Uma última constatação merece destaque: é possível que haja maus-tratos quando o pai deixa de alimentar seus filhos. Pode-se mesmo dizer que em razão do preceito cristão do dever de alimento entre ascendentes e descendentes, o ato de recusar alimentos ao filho pode ser considerado mais grave que o castigo físico. Além disso, essa recusa do pai pode lhe custar a perda do pátrio poder. Esta é a opinião do jurista Jean Duret (1610, p. 22) na sua obra Traicte des peines et amendes de 1610:

O pai não é somente exortado a nutrir a criança que ele colocou no mundo, isto é também para ele um dever e uma obrigação (...) se o filho não é bastardo ou incestuoso, e proveniente de casamento proibido, ou se ele não é ingrato ... não prestando a devida obediência aos seus parentes, se não for um desses casos, o pai se recusando a alimentar o filho perde o direito e o pátrio poder tal como lhe foi conferido pelas leis. ${ }^{22}$

\section{PIETAS}

Com relação à incorporação da ideia de pietas ao pátrio poder, ela remonta aos primeiros doutrinadores do cristianismo. Não cabe aqui entrar na discussão sobre a influência patrística e a interpolação desse termo no Corpus Iuris Civilis pela comissão Triboniana. ${ }^{23} \mathrm{O}$ que nos interessa é saber como a concepção de pietas evoluiu e se adaptou a um novo paradigma entre os séculos XVI e XVIII. De fato, todos os jurisconsultos estão convencidos de que a pietas está sempre presente na relação entre pai e filho, mesmo se antes a pietas deve ser observada perante Deus. ${ }^{24} \mathrm{O}$ vínculo que liga o filho ao pai é algo inelutável, proveniente de uma força natural e divina, a qual estabelece deveres morais entre os dois. Há, portanto, na mentalidade dos juristas uma grande confiança nos atos dos pais, o castigo físico presumido ser exercido sempre com pietas. ${ }^{25}$ Com o intuito de obter uma definição clara do conceito de pietas no Antigo Regime, faremos uma distinção entre "pitié" e pietas, e depois entre affectio e pietas com o auxílio dos dicionários da época.

O termo latino pietas ("piété", em francês) é híbrido. Na Antiguidade, ele podia significar um dever patriótico que se manifestava por uma devoção à pátria, ou um sentimento de gratidão com relação a um parente ancestral, ou então um sentimento de justiça com relação aos deuses (WAGENVOORT, 1980, p. 8). Nos textos jurídicos do final do Antigo Regime, o termo pietas é especificamente empregado quando se quer explicar a forma pela qual deve se estabelecer as relações entre pai e filho, e essa forma se aproxima da ideia de devoção. Já o termo francês "pitié" (piedade) significa compaixão com a "miséria de alguém”, com “um pobre" (NICOT, 1606, p. 483, $\mathrm{V}^{\circ}$ Pitié). A piedade é um estado de espírito que pode ser empregado a todas as relações humanas. É curioso notar que o termo "pitié" não integra o dicionário de Pasquier de 1552, e para encontrar sua menção deve-se buscar pelo termo "misère" (miséria). Nota-se, portanto, que no século XVII se verifica uma mudança conceitual do termo 
pietas. Se inicialmente ele se refere às relações entre parentes, notadamente entre pai e filho, no dicionário de Jean Nicot pietas e "pitié" são sinônimos, ambos definidos como piedade (NICOT, p. 483). Doravante, o termo se adapta ao conceito de piedade, segundo os preceitos cristãos, e exprime um sentimento de misericórdia e compaixão com os sofrimentos de alguém. No século XVIII, o jurisconsulto Jean Meslé, interpretando o direito romano, sintetiza a evolução do nosso conceito, e atribui ao termo pietas o sentido que fará for tuna nos séculos seguintes: "é do direito das gentes e comum a todo o gênero humano ter piedade diante de Deus, e ser obediente ao pai, à mãe e à pátria” (MESLE, 1752, p. 44).

A pietas também se distingue da "affection" (afeição), e aqui o exemplo dos tutores é bastante ilustrativo. Joost Damhouder, jurisconsulto do século XVI, afirma que o dever dos tutores é de "ter o lugar e o ofício de pais e mães, e de aportar aos pupilos uma afeição semelhante" (DAMHOUDER, 1567, p. 128). O autor teve o cuidado de dizer que a afeição deve ser apenas semelhante. De fato, os tutores não tiram sua autoridade sobre os pupilos de leis naturais e divinas, mas de leis humanas, não se presumindo haver nessa relação jurídica o sentimento de pietas, mas simplesmente uma afeição. Poderíamos ainda dar o exemplo da affectio maritalis, cuja definição é emprestada do direito romano, e depois assimilada ao direito canônico, para significar "état d'esprit amoureux" no âmbito do casamento. Nesse tipo de relação se presume uma afeição entre cônjuges, e não pietas (GAY, 2009, p. 293-294). Existe também uma distinção no campo da querela inoficiosa. Segundo o jurisconsulto Hyacinthe Boniface, o tipo de relação que se estabelece entre filhos, pais e ascendentes é diferente daquela que se estabelece entre colaterais e irmãos: a querela dos primeiros vem ex officio pietatis que é recíproca entre pai e filho, mas a querela dos irmãos não se procede dessa "piété", mas de fonte diferente (BONIFACE, 1689, p. 32). Aqui o termo pietas é juridicamente utilizado para identificar relação entre ascendente e descendente em linha direta.

Curioso notar que a partir do século XVII os juristas substituem o termo latino pietas pela palavra "amour" (amor), sobretudo para fazer a distinção entre o pátrio poder praticado no direito francês ("puissance paternelle”), que é de inspiração dos dogmas cristãos, ${ }^{26}$ e a patria potestas do direito romano. Boniface, citando a doutrina patrística, diz que "Tertuliano a este propósito, falando dos pais, afirma que o nome amor é mais agradável do que poder, gratius est nomen pietatis, quam potestatis, quando os pais não têm mais amor eles não são mais pais, e não devem, portanto, administrar seus filhos" (1689, p. 674). O que se espera nas relações entre pais e filhos não é mais um sentimento de devoção ou de piedade, mas sim de amor. Porém o sentido do termo "amor" não é o mesmo que conhecemos hoje. No Antigo Regime, ele transmite a ideia de respeito no sentido de dependência e submissão do filho aos pais. É neste sentido os ensinamentos de Jean Domat (DOMAT, 1777, Cap. 3, p. 6) quando diz que o temor e o respeito que os filhos devem ter em relação aos seus pais é fruto de um 
amor natural que é recíproco entre eles. Esse amor se forma primeiro entre os cônjuges com o casamento, e depois é transmitido aos filhos nascidos dessa união. A consagração do amor no casamento é a ideia central da doutrina de Domat. A partir de preceitos bíblicos, o autor articula o dogma do casamento com a ideia de amor paterno e o dever de obediência dos filhos. Será, de fato, essa concepção da obediência dos filhos um dever, articulado por Domat com base nos preceitos bíblicos, que inspirará os redatores do Código Civil de 1804. ${ }^{27}$

\subsection{O CONTROLE DO ENCARCERAMENTO DOS FILHOS NAS CASAS DE CORREÇÃO}

O estudo dos limites do direito dos pais de encarcerarem seus filhos nos remete ao complexo tema da prisão. Segundo a doutrina, inspirada no direito romano, a prisão não é concebida como um lugar para punir. Ela existia como um "lugar público... destinado a guardar os criminosos, e também às vezes os devedores nos casos em que eles são obrigados corporalmente, como o estelionato, e letras de câmbio, ou por despesas em virtude de um Aresto ou Sentença d'interato" (FERRIÈRE, 1769, t. 2, p. 376). A prisão também era um lugar onde os condenados, por meio da penitência, meditavam sobre os crimes cometidos antes de sofrerem a pena pronunciada pela justiça (CARBASSE, 2006, p. 316-317). Mas o encarceramento de pessoas para fins de punição e disciplina, sem que houvesse um pronunciamento por parte da justiça, era também comum. Aqui é preciso sublinhar a distinção entre prisão e encarceramento.

Havia na sociedade inúmeros estabelecimentos com vocação para servirem de encarceramento sem serem tecnicamente considerados uma prisão, tais como colégios, universidades, monastérios e conventos. ${ }^{28}$ A prática do encarceramento por essas instituições "privadas” fazia parte do poder de disciplina que era exercido contra pessoas que descumprissem as regras de obediência interna ou que praticassem condutas consideradas contrárias aos bons costumes. Normalmente essas instituições eram controladas pela Igreja, mas a partir do século XVI o poder régio cria instituições voltadas à prática do encarceramento. Criando o Hôtel dieu para os enfermos, o Hôpital général para assistência aos pobres e a Maison de force, chamada também de Maison de correction (Casas de correção), para disciplinar os filhos rebeldes, o poder régio passa a concorrer com a Igreja na administração dessas instituições (QUÉTEL, 2009 , p. 131). Doravante, esses estabelecimentos com vocação disciplinar são considerados, juntamente com a prisão, um lugar público, sob controle do Estado.

A prisão sempre foi considerada um lugar público de tal modo que o cárcere privado era assimilado ao crime de lesa-majestade e punido de morte. A assimilação entre esses dois crimes existe até o final do Antigo Regime. Segundo François Serpillon, jurista da segunda metade do século XVIII, todos os particulares, inclusive os Senhores da Alta Justiça, são proibidos de praticar cárcere privado e ter prisões iguais à da justiça régia, sob pena de serem punidos por crime de lesa-majestade (SERPILLON, 1767, p. 278). No mesmo sentido Ferrière: "não é permitido a ninguém reter uma 
pessoa em cárcere privado, e aquele que fizer de sua casa uma prisão violará a majestade do Príncipe. Até os Senhores da Alta Justiça são defesos de ter prisões nos seus castelos...” (1769, p. 387, $\mathrm{V}^{\circ}$ Prison). É verdade que a assimilação desses dois crimes tem um significado. Isso representa a vontade do monarca de obter o monopólio do ius puniendi. O cárcere privado é punido não só porque se presume o uso da violência - ato que fere a ordem pública -, mas também porque quem o comete concorre com a justiça régia, e fere a pessoa do Rei - daí a sua assimilação ao crime de lesamajestade. ${ }^{29}$ Poderíamos pensar que a repressão do crime de cárcere privado representaria um elemento forte para consolidar nas mãos do Rei o monopólio do poder de punir. Mas o encarceramento disciplinar sempre foi visto pela doutrina como um caso de exceção à proibição do cárcere privado. Como tolerar o uso do encarceramento disciplinar e punir o cárcere privado?

O direito de encarcerar pessoas era tolerado somente em certas relações de autoridade por se tratar de uma prática costumeira. O encarceramento do tipo disciplinar era um atributo do direito de correção de inúmeras autoridades domésticas, notadamente a autoridade paterna. Na segunda metade do século XVI, o jurisconsulto Jean Papon, no seu Recueils d'arrests notables des courts souveraines, afirma que "o pai pode encarcerar seu filho, o senhor seu servo, o marido sua mulher, sem incorrer à pena de prisão privada" (1568, Liv. 23, T. 1). Essas autoridades formavam, segundo Etienne Pasquier, a polícia do reino. ${ }^{30}$ Se existia, portanto, um caráter punitivo nesse tipo de encarceramento, a doutrina entendia apenas como manifestação do direito de correção. A medida tinha caráter disciplinar e não era considerada uma pena. Assim, o crime de cárcere privado representava somente de maneira simbólica uma afronta à justiça régia e à pessoa do Rei, o que tornava a sua punição uma medida politicamente ineficaz para o Estado obter o monopólio completo do poder de punir. Desde o século XIV, o poder régio pretendia esse monopólio, e o Rei, cada vez mais soberano, se arrogava o direito de persecução, instrução e de punição dos delinquentes. Esse processo de monopolização do poder de punir pelo Estado está também atrelado ao desenvolvimento da atividade administrativa estatal que se consolida no século XVIII, e tem origem na concepção de poder de polícia (DURAND, 1996). De fato, o controle do encarceramento disciplinar por parte do poder régio começa a ser realizado na metade do século XVI e se intensifica no século XVIII. E já em 1570 o costume d'Anvers antecipava o que se consolidaria nos séculos seguintes: "Se os pais quiserem colocar seus filhos... em prisão... eles devem colocá-los em qualquer lugar público e conhecido da cidade..., e isto com o consentimento do magistrado, e somente dessa forma..." (DEMARS-SION, 2000, p. 434, nota 30).

Durante o século XVIII a proliferação de estabelecimentos públicos de vocação disciplinar revela a preocupação do Rei para assumir o controle do direito de correção. A chancelaria real coloca em prática essa política de controle oferecendo àqueles que desejassem encarcerar a título disciplinar um filho, ou qualquer outro membro da 
família, ou até mesmo um vizinho, o instrumento legal das lettres de cachet. Sabe-se que o seu uso contra filhos rebeldes para corrigir seus desvios de conduta e devassidão foi bastante utilizado na sociedade francesa (QUETEL, 1981; FARGE, 1982). Os estabelecimentos dotados de competência para o encarceramento correcional os recebiam mediante uma pensão que era paga pelo pai durante o período de detenção. Aos poucos o que era uma medida de disciplina interna, destinada a sancionar as faltas cometidas por membros de uma instituição, passa a ser negociada com pais descontentes com a conduta de seus filhos.

Mas esse direito de correção dos pais, até então tolerado, recebeu limitações por parte do poder régio a partir do final do século XVII. Isso é o resultado de inspeções exercidas por funcionários da administração régia ao interior das casas de correção. Uma decisão de 1672 ordena que dois conselheiros e um substituto do Procuradorgeral do rei procederão à inspeção das Casas de correção, devendo ser realizado um relatório e entregue à Corte contendo informações sobre "idade, estado e qualidade das pessoas detidas por forma de correção”. ${ }^{31}$ De acordo com o relatório da primeira visita realizada:

[...] havia várias pessoas detidas nas prisões dessa cidade, e particularmente naquela do templo de São Martinho, sob pretexto de correção, por ordem dos juízes dos senhorios da alta justiça, sem a anuência de seus parentes, alguns ainda de idade bem avançada, engajados em ordens, e outros casados $[\ldots]$.

Alguns meses mais tarde, em 9 de março de 1673, o Procurador-geral do rei constata a existência de "abusos de autoridade paterna e materna (julgamentos domésticos) na detenção de menores a título de correção”. Segundo o relatório:

[...] vários abusos no uso e no limite desse poder em que algumas pessoas, casadas em segundas núpcias, não deixam de praticar contra as crianças do primeiro casamento; e que mesmo as mães, algumas mesmo depois do segundo casamento, e também outros parentes, que na falta de pai e mãe [cometem esses abusos]; que desde algum tempo não existia idade limite que restringisse esses julgamentos domésticos, encontrando-se nas prisões homens com idade de mais de 30 anos [...].

Com base nesses relatórios, o Parlamento de Paris pronuncia arrêts de reglements para impor limites ao direito dos pais. Duas condições impedem os pais de exercerem o direito de correção de maneira discricionária: 1) o filho ter idade de vinte e cinco anos ; e 2) o pai não ter convolado em segundas núpcias. ${ }^{32} \mathrm{~A}$ idade limite imposta é de inspiração do direito romano a qual, na época, é também do costume de Paris. 
Essas condições não são cumulativas, e a presença de uma delas é suficiente para impedir o direito do pai. Neste caso, o exercício do direito de correção fica condicionado à autorização judicial. Antes de decidir, o magistrado pode ainda consultar o conselho de parentes; e esta consulta deve sempre ser realizada quando tutores e outros parentes desejam encarcerar os menores. Cabe dizer que somente com relação aos filhos do primeiro casamento operam tais condições, os filhos naturais (não legitimados) e os ilegítimos não estão abrangidos pelo regulamento. Ainda, segundo o regulamento, durante o casamento somente o pai poderia encarcerar diretamente os filhos menores na Casa de correção, proibindo esse direito às mães. Trata-se apenas de limites, o que significa que a regulamentação baixada pelo poder régio não tem a finalidade de retirar o direito de correção dos pais, estes o conservam de maneira absoluta para todos os outros casos. Seria inútil dizer que essa regulamentação destina-se exclusivamente às famílias legítimas, ou seja, aquela formada a partir de um matrimônio realizado segundo os preceitos cristãos. Essas limitações servirão de fundamento para os artigos 375 e seguintes do Código civil de $1804 .{ }^{33}$

\section{CONCLUSÃO}

Ao termo deste breve estudo, podemos concluir que as origens dos limites ao exercício do direito de correção paternal são, em um primeiro momento, uma adaptação para o direito francês da legislação romana do baixo império, na qual a instituição da patria potestas é articulada de maneira racional às ideias cristãs. Isso se nota com evidência para os limites da correção pelo castigo físico em que a noção de moderação é extraída do ajuste entre as ideias de atrocidade e piedade.

As origens dos limites do direito de correção paternal estão também arraigadas ao processo de consolidação do direito de punir nas mãos do Estado e, por via de consequência, ao processo de formação do seu poder de polícia. A partir do século XVI, o poder régio cria mecanismos jurídicos para limitar a magistratura doméstica. Se o pátrio poder é uma instituição de caráter político, na medida em que a sua manutenção é de interesse do Estado, o poder do pai não pode, entretanto, concorrer com o poder do Rei. Daí a existência de limites judiciários ao exercício do direito de correção, sobretudo no tocante à execução da sanção, quando é defeso ao pai aplicar uma pena no filho rebelde. Daí também o controle do encarceramento disciplinar a partir do século XVII. E neste campo o poder régio encontrou dificuldades para controlar o direito de correção paternal, o que se verifica pela ineficácia do mecanismo de assimilação entre o crime de cárcere privado e o crime de lesa-majestade. Assim, em vez de sancionar os pais, o poder régio se colocou em uma posição ambígua, tratando de facilitar e, ao mesmo tempo, limitar o direito de correção deles. 


\section{NOTAS}

1 No continente europeu um movimento de abolição de toda forma de castigo físico contra crianças ganhou força no seio do Conselho da Europa. Dos 47 países-membros do CE, somente 21 proíbem formalmente o castigo físico em suas legislações, ou seja, menos da metade. Os países e a data em vigor da respectiva legislação são os seguintes: Suécia (1979), Finlândia (1984), Noruega (1987), Áustria (1989), Portugal (1994), Chipre (1994), Letônia (1998), Dinamarca (1997), Croácia (1999), Alemanha (2000), Bulgária (2000), Islândia (2003), Romênia (2004), Hungria (2004), Ucrânia (2004), Grécia (2006), Holanda (2007), Espanha (2007), Moldávia (2008), Luxemburgo (2008), Polônia (2010); e no mundo, apenas 32 países integraram essa lista. Informações extraídas do site: <http://www.endcorporalpunishment.org/ pages/frame.html>.

Na França há Projeto de Lei n. 2.244, de 22 de janeiro de 2010, para abolir o castigo físico de crianças, mas que ainda não foi sancionado. No Brasil, o artigo 1.638 do Código Civil autoriza o castigo físico exercido de maneira moderada ("Perderá por ato judicial o poder familiar o pai ou a mãe que: I - castigar imoderadamente o filho"), e desde 2003 existe Projeto de Lei n. 2.654/2003, que se tornou Projeto de Lei n. 7672/2010, sobre a alteração desse artigo do Código Civil, e do artigo 130 da Lei n. 8.069/90, o Estatuto da Criança e do Adolescente, estabelecendo o direito da criança e do adolescente a não serem submetidos a qualquer forma de punição corporal mediante a adoção de castigos moderados ou imoderados, sob a alegação de quaisquer propósitos, ainda que pedagógicos.

2 A Lei de 1935 apenas retira o direito dos pais de encarcerar os filhos diretamente, isto é, sem auxílio de autorização judicial. O encarceramento dos filhos por forma de correção somente desaparecerá com uma lei de 23 de dezembro de 1958 .

3 Artigo 378-1: "Podem ser retirados totalmente da autoridade parental, independente de qualquer condenação penal, o pai e mãe que, seja por maus-tratos, seja por consumo habitual e excessivo de bebidas alcoólicas ou uso de entorpecentes, seja por má conduta notória ou por comportamentos delituosos, seja por falta de cuidados ou falta de direção, coloquem manifestamente em perigo a segurança, a saúde ou a moral da criança" (a tradução de todos os textos em francês para a língua portuguesa foi realizada pelo próprio autor).

4 No direito romano clássico o paterfamilias detinha o direito de vida e de morte sobre os seus filhos, o vitae necisque potestas. A origem e o desuso dessa correção capital do pai romano suscitaram inspirados debates junto aos romanistas (CORNIL, 1897; ALBANESE, 1948; THOMAS, 1984).

5 Permito-me citar comunicação de minha autoria intitulada "Considérations sur le droit de correction dans l'ancien droit, du XVIe au XVIIIe siècle” apresentada no colóquio La peine et le Code pénal de 1810. La dimension historique de la peine avant, pendant et après le Code pénal de 1810 (versão escrita a ser publicada).

6 Este estudo situa-se, em larga perspectiva, sob o paradigma da Sozialdisziplinierung (disciplina social) introduzido em 1968 no domínio da historiografia por Gerhard Oestreich para explicar o processo de mutação cultural da Europa na época moderna. Este trabalho deve ser colocado em direta relação com os de Norbert Elias (1939) e de Michel Foucault (1975). Do ponto de vista metodológico, o conceito de disciplina como um "instrumento, exercício, organização da força social de cada individuo" (P. SCHIERA, 1992, p. 316) já foi utilizado em estudos de história do direito. Para o Brasil, conferir o estudo de Andrei Koerner (2006) que toma como modelo a Casa de correção da Corte para estudar as práticas de punição e disciplina da sociedade escravista. Conferir também Daniela Frigo (1991) que se apoia na doutrina quinhentista e seiscentista para identificar a "doutrina da economia" no âmbito da autoridade doméstica e de sua transposição como "modelo de gestão" ao poder político do rei. Ver, igualmente, António Manuel Hespanha (1993) que insere o paradigma da disciplina social no âmbito da política penal do Antigo Regime em Portugal.

7 Sobre o processo de formação do poder de polícia do Estado durante o Antigo Regime, a bibliografia é numerosa. Na bibliografia brasileira conferir Seelaender (2009); para o direito francês ver Durand (1996); e para o direito alemão ver a obra organizada por Stolleis (1996), o estudo de Härter (1994), e o de Napoli (1997) que situa o tema na "era liberal".

8 Esse estado de concorrência se verifica com nitidez quando o direito de correção do pai de família se exerce pelo encarceramento disciplinar.

9 De acordo com o artigo 65 do costume de Montpellier: "Os furtos, roubos e injúrias praticados pelos domésticos são corrigidos pelos senhores que são seus magistrados, de modo que eles não estão obrigados a se presentarem perante 
a justiça. Entendemos por domésticos: esposa, servos, libertos, mercenários, filhos e netos, discípulos e escolares, auditores et mares omnes e as mulheres de família" (Domestica furta vel rapine vel injurie domestice corrigantur a dominis seu a magistris, ita quod non teneantur reddere curie; nec castigati de castigatione audiantur in curia; domesticos autem intelligimus: uxorem, servos, libertos, mercenarios, filios vel nepotes, discipulos vel scolares, auditores et mares omnes et feminas qui sunt de família).

10 "Se o teu filho está sob teu poder, ele não poderia alienar os bens que havia (previamente) adquirido para você. Se ele não reconhecer a piedade que é devida a um pai, você não está impedido de puni-lo por exercer o pátrio poder. Você pode fazer uso de um remédio mais forte se ele persistir na mesma contumácia, e você pode entregá-lo ao governador provincial para pronunciar a sentença que você desejar que seja pronunciada." (Si filius tuus in potestate tua est, res adquisitas tibi alienare non potuit: quem, si pietatem patri debitam non agnoscit, castigare iure patriae potestatis non prohiberis, artiore remedio usurus, si in pari contumacia perseveraverit, eumque praesidi provinciae oblaturus dicturo sententiam, quam tu quoque dici volueris)

11 "Nós permitimos às pessoas mais velhas de infligir aos menores próximos a eles castigos proporcionados a suas faltas a fim de que aqueles que os bons exemplos domésticos não puderam levá-los a ter uma vida honesta sejam constrangidos pela correção. Nós não os autorizamos, entretanto, o direito de infligir fortes punições a seus menores próximos, mas somente a faculdade de castigá-los como convém ao pátrio poder, e de punir seus desvios e de reprimi-los por uma correção doméstica. Mas se a atrocidade do fato exceder os limites de uma correção doméstica, nós ordenamos que o culpado seja levado aos tribunais." (In corrigendis minoribus pro qualitate delicti senioribus propinquis tribuimus potestatem, ut, quos ad vitae decora domesticae laudis exempla non provocant, saltem correctionis medicina compellat. Neque nos in puniendis morum vitiis potestatem in immensum extendi volumus, sed iure patrio auctoritas corrigat propinqui iuvenis erratum et privata animadversione compescat. Quod si atrocitas facti ius domesticae emendationis excedit, placet, enormis delicti reos dedi iudicum notioni)

12 O procedimento do hors de cour et de procès se aplica "quando não há provas suficientes para condenar o acusado, nem para absolvê-lo plenamente” (DENISART, 1777, p. 483).

13 Ver também aresto da Corte de Dijon (sem data) onde uma mãe acusa o filho perante a justiça e depois o perdoa. Mas sem considerar o perdão da mãe os juízes condenam o filho a fazer amende honorable diante da porta da Igreja de Notre Dame de Dijon além de condená-lo a nove anos de galês (SERPILLON, 1767, T. 10, art. 8). Igualmente o aresto de 1578 em que um filho foi condenado ao açoite pelo Procurador do rei de Sammar sem considerar o perdão da ofensa feita pelo pai (BOUCHEL, 1629, $\mathrm{V}^{\circ}$ Injure).

14 Digesto 48, Título 9: Da lei Pompeia sobre os parricídios: "Reporta-se que o imperador Adriano, tendo julgado um homem que havia matado durante uma caça seu filho que era adúltero de sua madrasta, foi deportado para uma ilha; porque ele havia cometido o assassinato mais como um ladrão do que usando o direito de pai; o pátrio poder deve consistir em piedade, e não em atrocidade" (Digeste 48, 9, De lege Pompeia de parricidiis: Divus Hadrianus fertur, cum in venatione filium suum quidam necaverat, qui novercam adulterabat, in insulam eum deportasse, quod latronis magis quam patris iure eum interfecit: nam patria potestas in pietate debet, non atrocitate consistere).

15 Entre outros deveres dos pais, podemos elencar o dever de alimentar os filhos - qui fait l'enfant doit le nourrir (LOISEL, 1846, t. 1, n. 58) -, o dever de educar os filhos e de estabelecê-los - daí vem o dever de dotar a filha (GAILHBAUD, 1928, p. 36) -, e o dever de donner un métier ao filho. Foi a partir de uma reflexão sobre os deveres do pai de família que Karen Fiorentino (2009) estudou o pátrio poder durante o período da Revolução Francesa.

16 “Art. 611. Se a criança comete um ilícito contra alguém quando está sob o poder de seu pai, o pai deve pagar uma multa civil, porque ele deve castigar seus filhos."

17 Provérbios do Antigo Testamento dizem: "Castiga o teu filho enquanto há esperança, mas não deixes que o teu ânimo se exalte até o matar” (Prov. XIX/18); “A estultícia está ligada ao coração da criança, mas a vara da correção a afugentará dela” (Prov. XXII/15); "A vara e a repreensão dão sabedoria, mas a criança entregue a si mesma envergonha a sua mãe” (Prov. XXIX/15); “Castiga o teu filho, e te dará descanso; e dará delícias à tua alma” (Prov. XXIX/17).

18 No dicionário de Estienne-Pasquier atrocitas significa Oultrage, Cruaulté, Felonnie (1552, V ${ }^{\circ}$ Atrocitas, p. 134). No dicionário de Jean Nicot encontramos a definição de atrocitas pelo termo enormité (1606, p. 233, $\mathrm{V}^{\circ}$ Enormité).

19 A noção de atrocitas foi apropriada pelas jurisdições eclesiásticas para inventar a categoria de enormitas (THERY, 2011). 
20 Certos médicos atribuíam aos açoites funções de cura. Ver, por exemplo, a obra Flagellum salutis de 1698 editada em Frankfurt pelo médico Christian Franz Paullini que considera a hostilidade de uma fustigação como um eficaz remédio para extirpar certas doenças, tais como a melancolia, a paralisia, o inchaço no bócio e o aborto.

21 A definição do crime de injúria no antigo direito penal diverge daquela do direito atual, e agressões físicas entram nessa categoria penal. Do latim injuria (in, contra, e ius, iuris, direito), a injúria é, lato sensu, definida como toda ação contrária ao direito; e em stricto sensu como uma investida oral ou física que atenta contra a integridade física ou moral de uma pessoa.

22 Segundo Pothier, "recusar a uma criança indigente os alimentos necessários, mesmo que ela tenha cometido uma grave ofensa contra seus pais, seria de alguma maneira render-se culpado de homicídio perante Deus” (1831, Part. 5, Cap. 1, n. 385).

23 A influência cristã sobre a patria potesta do período clássico - condenando os seus rigores e transformando o seu conteúdo - é atestada na doutrina de Tertuliano já no século III a.C. (ROBERTI, 1933; GAUDEMET, 1959).

24 "O dever, ou o amor e a obediência que devemos primeiramente com relação a Deus, e depois com relação a seus pais e mães, e filhos, e outros parentes próximos." (PASQUIER, 1552, p. 1003, $\mathrm{V}^{\circ}$ Pietas).

25 Jean Bodin afirma que "seria impossível os pais punirem seus filhos sem uma causa boa e justa porque a afeição e o amor dos pais e mães com os filhos são tão grandes que a lei sempre presumiu que tudo que eles fizessem sempre seria em proveito e honra dos filhos" (1986, Liv. I, Cap. 4, p. 75).

26 Pode-se ler num aresto de 1686: "dando os justos limites ao imenso poder que as antigas leis atribuíam aos pais sobre os filhos, colocamos de lado o que era contrário ao espírito do cristianismo” (BLONDEAU, 1700, p. 604). Uma ideia bem propagada na Idade Média, e ainda hoje defendida, é o papel "humanista" desempenhado pelo cristianismo no direito romano considerado para o cristão como bárbaro. A perpetuação dessa ideia no século XIX deve-se a obra de Raymond Théodore Tropolong (1843).

27 Art. 371-1 do atual Código Civil francês: "A criança, a toda idade, deve honrar e respeitar seu pai e sua mãe" (L'enfant à tout âge, doit honneur et respect à ses père et mère). Regra de inspiração bíblica: "Honre teu pai e tua mãe" (Êxodo XX/12), "Que cada um de vocês respeite seu pai e sua mãe" (Lev. XIX/3), "Crianças, respeitem seus parentes" (Ef. VI/1). Num estudo sobre a origem desse artigo nos debates preparatórios ao Código Civil de 1804, Xavier Martin indaga se quando os redatores exprimem "honra e respeito", eles na realidade querem dizer "submissão e obediência" (1992, p. 277).

28 "Que aquele que é alojado num quarto situado na cidade pode com mais facilidade deixar-se levar pela devassidão. Entretanto, a ideia de pais e mães de encarcerarem seus filhos dentro de colégios foi bastante sábia, porque através desse expediente os filhos são compelidos a acostumar-se ao estudo, e de uma só vez se imprime sobre suas almas a imagem dos bons hábitos." (PASQUIER, 1633, Liv. 9, Cap. 18, p. 381)

29 Temos aqui um exemplo de assimilação entre "corpo físico" do Rei e "corpo político" do reino, ideia que tem origem na teoria política medieval (KANTOROWICZ, 1997).

30 “... em nossa polícia em matéria de comando e obediência, ela se refere, por um lado, ao público de maneira total, como é a autoridade dos magistrados sobre o povo e aquela do bispo sobre o clero e, por outro lado, ela se refere ao particular e ao doméstico que marca o poder do pai dentro de sua casa com relação ao seu filho, do marido com relação a sua mulher...” (1610, p. 64).

31 Todas as informações que seguem foram extraídas do estudo de P. Sérieux (1938) sobre a intervenção do Parlamento de Paris no controle do encarceramento correcional.

32 Essa condição é fruto de julgados anteriores envolvendo o direito de correção paternal que é, na realidade, uma interpretação extensiva da Novelae 22, Caput XXXVIII: “... que a mãe é vista como mais digna de confiança para a educação dos filhos ... se ela não passar em segundas núpcias” (... quoniam omnium mater fide dignior ad filiorum educationem videbatur ..., nisi ad secundas accesserit nuptias). No Parlamento da Bretanha, de acordo com a decisão prolatada em 1559, a madrasta e o pai são acusados de maltratar a jovem Jeanne Lanté (DU FAIL, 1654, Liv. 2, Chap. 93, p. 532-533). Quase 
um século depois (em 1644), o Parlamento de Toulouse julga um caso em que um pai casado quatro vezes se recusa de fornecer subsídios para o tratamento do filho doente do seu primeiro casamento (PLANTEAU DE MAROUSSEM, 1887, p. 151). Em 1675, neste mesmo Parlamento, a guarda dos filhos é retirada de um pai casado em secondes noces acusado de praticar maus-tratos, acusação que foi também dirigida contra a madrasta (ROCHE-FLAVIN, $1682, \mathrm{~V}^{\circ}$ Serviteur et servantes). No final do século XVIII, no Parlamento de Provença, um pai e a sua segunda esposa são acusados de maltratar a jovem Marguerite Caillot (MERLIN, 1828). Todos esses julgados estão baseados numa ideia bem propagada na doutrina do direito comum segundo a qual os sentimentos naturais de afeição do pai ou da mãe com relação aos filhos do primeiro casamento são, segundo uma experience journaliere et continuelle, alterados e corrompidos pelo segundo casamento. Como afirmou Boniface, jurista provençal do século XVII, com um segundo casamento "não há segurança na casa do pai, seja pelas induções da madrasta, seja pelo amor do pai pelos seus filhos do segundo casamento, os movimentos de afeição [com os filhos do primeiro casamento] se alteram; é o que acontece quase sempre” (BONIFACE, 1689, p. 674).

33 Art. 375: "O pai que terá motivos de descontentamentos muito graves sobre a conduta de uma criança, terá os seguintes meios de correção". Art. 376: "Se a criança tem idade de dezesseis anos começados, o pai poderá o deter durante um tempo que não poderá exceder um mês; e, para este efeito, o presidente do tribunal d'arrondissement deverá, sob sua demanda, expedir ordem de prisão". Art. 377: "A partir da idade de dezesseis anos começados até a maioridade ou a emancipação, o pai poderá somente requerer a detenção do seu filho por até seis meses; ele se dirigirá ao presidente do tribunal, que, depois de ter verificado a demanda junto ao comissário do Governo, expedirá a ordem de prisão ou a recusará, e poderá, no primeiro caso, abreviar o tempo de detenção requerido pelo pai”.

\section{REFERÊNCIAS BIBLIOGRÁFICAS}

\section{Fontes}

AGOSTINHO, Bispo de Hipona. Confissões, Liv. 1, Ch. 7.

BASSET, Jean-Guy (1738). Notables arrests de la cour de Parlement, aydes et finances de Dauphiné, t. 2, Grenoble.

BODIN, Jean (1986) [1. ed. 1576]. Les Six livres de la République, Fayard, Paris.

BONIFACE, Hyacinthe (1670 e 1689). Arrêts notables de la cour du Parlement de Provence, 5 vols., Lyon (1670), e

Paris (1689).

BOUCHEL, Laurent (1629). La Bibliothèque ou thrésor du droict françois recueilly et mis en ordre, Paris.

CLEMENTINI, Ascanii (1571). Tractatus de patria potestate, Venise.

D'ARGENTRÉ, Bertrand (1628). Coustumes générales du pays et duché de Bretagne, Rennes.

DAMHOUDER, Joost (1555). La Pratique et enchiridion des causes criminelles, Louvain.

(1567). Le refuge et garand des pupiles, orphelins, et prodigues, Anvers.

DENISART, Jean-Baptiste (1777). Collection de décisions nouvelles et de notions relatives à la jurisprudence actuelle, t. 2, Paris.

DOMAT, Jean (1777) [1. de. 1689]. Loix civiles dans leur ordre naturel, t. 1, Paris.

DU FAIL, Noël (1654). Memoires des plus notables et solemnels arrests du Parlement de Bretagne, Rennes.

DURET, Jean (1610) [1. ed. 1573]. Traicte des peines et amendes tant pour les matieres criminelles que civiles, Lyon.

EXPILLY, Claude (1631). Plaidoyez de M. Claude Expilly, Lyon.

FERRIÈRE, Claude-Joseph de (1769). Dictionnaire de droit et de pratique, t. 2, Paris.

JOURNAL DU PALAIS DE BLONDEAU ou Recueil des principales décisions de tous les Parlements et Cours souveraines de France (1700), 1660-1700, 4. ed. Paris.

JOUSSE, Daniel (1771). Traité de la justice criminelle de France, t. 1, Paris.

LOISEL, Antoine (1846) [1. ed. 1607]. Institutes coutumieres, Paris.

MERLIN, Philippe-Antoine (1828). Répertoire universel et raisonné de jurisprudence, t. 13 ( $\mathrm{V}^{\circ}$ Puissance paternelle), Paris. MESLÉ, Jean (1752). Traité des minorités, tutelles et curatelles, v. 1, Paris.

NICOT, Jean (1606). Le thresor de la lengue françoyse, tant ancienne que moderne, Paris.

PAPON, Jean (1568) [1. ed. 1556]. Recueils d'arrests notables des courts souveraines de France, Paris.

PASQUIER, Estienne (1552). Dictionarium latinogallicum, Paris.

(1610). L'interpretation des institutes de Justinian, Paris.

(1633). Les recherches de la France, Paris.

PLANTEAU DE MAROUSSEM, Pierre-Robert (1887). Essai de théorie sur la nature de l'émancipation en droit romain: du contrôle de la justice sur les droits paternels de correction et d'éducation en droit français, thèse faculté de droit de Paris. 
POTHIER, Robert-Joseph (1831) [1. ed. 1778]. Oeuvres de Pothier: Traité du contrat de mariage et de la puissance du mari, t. 3, Bruxelles.

ROCHE-FLAVIN, Bernard de la (1682). Arrests notables du Parlement de Toulouse, t. 5, Toulouse.

SERPILLON, François (1767). Code criminel ou commentaire sur l'ordonnance de 1670, t. 1, Lyon.

TROPOLONG, Raymond Théodore (1843). L'influence du christianisme sur le droit civil des Romains, Paris.

\section{Trabalhos acadêmicos}

ALBANESE, Bernardo (1948). "Note sull'evoluzione storica del ius vitae et necis", Scritti Ferrini, vol. III, Milano, p. 343-366.

AUBENAS, R. J. (1964). "Quelques réfléxions sur le problème de la pénétration du droit romain dans le Midi de la France au Moyen Âge”, Annales du midi, t. 76, Toulouse, 1964, p. 371-377.

CARBASSE, Jean-Marie (2006). Histoire du droit pénal et de la justice criminelle, Paris.

CORNIL, Georges (1897). "Contribution à l'étude de la patria potestas", Nouvelle Revue historique de droit français et étranger, 21, p. 417-485.

DELMAS-MARTY, Mireille (1995). "Réflexions sur le pouvoir disciplinaire”, Revue trimestrielle des droits de l'homme, n. 22 (6éme année - 1er avril), p. 154-160.

DEMARS-SION, Veronique (2000). "L'enfermement par forme de correction paternelle", Revue historique de droit français et étranger, 78 (3), juill.-sept., p. 429-472.

DURAND, Bernard (1996). "La Notion de Police en France du XVIe au XVIIIe siècle", Policey im Europa der Frühen Neuzeit, Michael Stolleis (Org.), Frankfurt am Main, p. 163-211.

ELIAS, Norbert (1939). Über den Prozeß der Zivilisation, 2 voll., Basileia: Verlag Haus zum Falken. Traduzido para o português: O processo civilizador, I: Uma história dos costumes, II: Formação do Estado e civilização, 2. ed. Rio de Janeiro, 2011.

FARGE, Arlette et FOUCAULT, Michel (1982). Les désordres des familles. Lettres de cachet des archives de la Bastille, Gallimard, Paris.

FIORENTINO, Karen (2009). "La puissance paternelle en Provence: une juridiction domestique tempérée par des devoirs”, Revue historique de droit français et étranger, n. 1, janv.-mars, p. 1-40.

FOUCAULT, Michel (1975). Surveiller et punir. Naissance de la prison, Gallimard, Paris.

FRIGO, Daniela (1991). "Disciplina Rei Familiariae: a Economia como Modelo Administrativo de Ancien Régime”,

Penélope, n. 6, p. 47-62.

GAILHBAUD, M. (1928). L'autorité du père de famille dans la coutume et jurisprudence du Parlement de Toulouse aux XVIe et XVIIIe siècles, Toulouse.

GARNOT, Benoît (1998). "La violence et ses limites dans la France du XVIIIe siècle : l'exemple bourguignon", Revue historique, t. 297/2, Paris, p. 237-253.

GAUDEMET, Jean (1959). "Parents et enfants dans la doctrine patristique et la législation conciliaire du BasEmpire", Études d'histoire du droit privé offertes à Pierre Petot.

GAUVARD, Claude (1997). “La justice pénale du roi de France à la fin du Moyen Âge”, Le pénal dans tous ses états, Justice, États et Sociétés en Europe, XIIe-XXe siècles, Xavier Rousseaux e René Lévy (orgs.), Bruxelles, p. 81-112.

GAY, Manuel (2009). "Du consentement à l'affectio maritalis: quatre mariages princiers (France-Angleterre, 1395 1468)”, Revue historique, n. 650, avril, Puf, Paris, p. 293-294.

HÄRTER, Karl (1994). "Disciplinamento sociale e ordinanze di polizia nella età moderna” (tradução da língua alemã para o italiano por Chiara Zanoni Zorzi), Disciplina dell'anima, disciplina del corpo e disciplina della società tra medioevo ed età moderna, Instituto storico italo-germanico in Trento, Bologna, p. 635-658.

HESPANHA, António Manuel (1993). "Da Iustitia à disciplina, textos, poder e política penal no antigo regime”, Justiça e litigiosidade: História e prospectiva, Lisboa, Fundação Calouste Gulbenkian, p. 287 e s.

HILAIRE, Jean (1968-1969). "Patria potestas et pratique montpelliéraine au Moyen Âge: symbolisme du droit écrit”, Société pour l'histoire du droit et des institutions des anciens pays bourguignons, comtois et normands, Dijon, p. 434.

KANTOROWICZ, Ernst Hartwig (1997). The King's Two Bodies: A Study in Mediaeval Political Theology, Princeton University Press.

KOERNER, Andrei (2006). "Punição, disciplina e pensamento penal no Brasil do século XIX", Lua Nova, 68, São Paulo, p. 205-242.

LAINGUI, André (1970). La responsabilité pénale dans l'ancien droit (XVIe-XVIIIe siècle), Paris.

MARROU, H.-I (1934). “Doctrina” et “disciplina” dans la langue des Pères de l’Église”, Bulletin Du Cange, 19, Paris, p. 5-25.

MARTIN, Xavier (1992). “A tout l'âge ? Sur la durée du pouvoir des pères dans le Code Napoléon”, Revue d'histoire des facultés de droit et de la science juridique, n. 13, p. 227-301. 
NAPOLI, Paolo (1997). "Police” et "Polizei”: deux notions à l'âge libéral”, La science juridique française et la science juridique allemande de 1870 à 1918, Olivier Beaud e Patrick Wachsmann (orgs.), Strasbourg, p. 79-100. QUÉTEL, Claude (2009). Histoire de la folie. De l'Antiquité à nos jours, Tallandier, Paris.

(1981). De par le roi: essai sur les lettres de cachet, Privat, Paris.

ROBERTI, M (1933). "Patria potestas e paterna pietas", St. Albertoni, 1, p. 259 e s.

SCHIERA, Pierangelo (1992). "Disciplina, disciplinamento", Annali dell'Istituto storico italo-germanico in Trento, XVIII, p. 315-334.

SCHMITT, Jean-Claude (1998). "Le corps en Chrétienté", La production du corps, Maurice Godelier et Michel Panoff (Org.), éditions des archives contemporaines, p. 340.

SCHNAPPER, Bernard (1991). "La correction paternelle et le mouvement des idées au XIXe siècle (17891935)", Voies nouvelles en histoire du droit. La justice, la famille, la répression pénal (XVIème-XXème siècles), Presses Universitaires de France, Paris, p. 523-553.

(1991b). "La répression pénale au XVIe siècle, l'exemple du Parlement de Bordeaux (15101565)”, Voies nouvelles en histoire du droit. La justice, la famille, la répression pénal (XVIème-XXème siècles), Presses Universitaires de France, Paris, p. 53-105.

(1972). "Observations sur les crimes atroces dans l'ancien droit pénal”, Revue historique du droit français et étranger, a-50, n. 4, p. 684-685.

SEELAENDER, Airton Cerqueira Leite (2009). “A 'polícia' e as funções do Estado - notas sobre a 'polícia' do Antigo Regime”, Revista da Faculdade de Direito - UFPR, Curitiba, n. 49, p. 73-87.

SÉRIEUX, Paul (1938). "Le Parlement de Paris et la surveillance des maisons d'aliénés et de correctionnaires aux XVIIe et XVIIIe siècles”, Revue Historique de droit français et étranger, quatrième série, dix-septième année, p. 404-459.

STOLLEIS, Michael (Org.) (1996). Policey im Europa der Frühen Neuzeit, Frankfurt am Main.

THERY, Julien (2011). "Atrocitas/Enormitas. Pour une histoire de la catégorie d' "énormité" ou "crime énorme” du Moyen Âge à l'époque moderne”, Clio@Thémis, n. 4:

http: / / www.cliothemis.com/Atrocitas-enormitas-Esquisse-pour).

THOMAS, Yan (1984). "Vitae necisque potestas, le père, la cité, la mort", Du châtiment dans la cité, supplices corporels et peine de mort dans le monde antique, Collection de l'Ecole française de Rome, n. 79, p. 53.

WAGENVOORT, Hendrik (1980). Pietas. Selected studies in Roman religion, Leiden.

\section{Alan Wruck Garcia Rangel}

Université de Strasbourg, França Bâtiment L'Escarpe, 11 rue du Maréchal Juin, 67046 Strasbourg - France alan.wrucklagmail.com
Doutorando VINCULADO AO CENTRE DE DROIT PRIVÉ FONDAMENtal, Université de Strasbourg (França) ATTACHÉ TEMPORAIRE D'ENSEIGNEMENT ET DE RECHERCHE (ATER) NA MESMA UNIVERSIDADE 